\title{
Collection Development Strategies for a University Center Library
}

\author{
Charlene S. Hurt, Laura O. Rein, Maureen \\ S. Connors, John C. Walsh, and Anna C. Wu
}

\begin{abstract}
Building a new library and developing an entirely new collection is always a daunting task. When the intent is to make that library a uniquely integrated component within a university center for student life, and to make the collection a pioneering one combining multiculturalism, diversity, and core texts, the task becomes even more challenging. This paper examines in detail the processes, policies, and procedures used to develop the collection of just such a library.
\end{abstract}

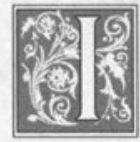

n 1990 the librarians of George Mason University (GMU) accepted the challenge to develop a unique collection of materials for a new kind of library. The university proposed to build a combined library/student center which would both literally and figuratively become the center of campus. The University Center Library (UCL) would combine a state-ofthe-art electronic library and media center with a teaching library focused on resources for the general education requirements of the undergraduate curriculum. This centrally located new building would sit just a block away from the existing main library.

GMU is a state-supported graduatelevel university with nearly 24,000 students, more than 7,000 of whom are graduate students, and has more than 100 degree-granting programs. It is the only state-supported university in northern Virginia, which has a large, well-educated, suburban population and a significant information industry base, as well as strong ties to the nation's capital. The university, founded as a branch of the University of Virginia in 1957 and chartered as an independent university in 1972 , is developing campuses with defined centers of excellence in the three largest counties in northern Virginia. The library system supports all of the campuses, primarily through provision of a wide variety of electronic resources and specialized librarian reference/research assistance at each site.

Given the rapid growth of its parent institution and the need to serve multiple campuses with limited resources, the library system emphasizes access to information and provision of electronic, networked sources of information. It also

Charlene S. Hurt is Director of Libraries at George Mason University (GMU), Fairfax, Virginia; Laura O. Rein is Director of Eden-Webster Libraries, St. Louis, Missouri; Maureen S. Connors is Social Sciences Reference/Liaison Librarian at GMU's Fenwick Library; John C. Walsh is Associate Librarian for Collection Development at GMU Libraries; Anna C. Wu is Assistant Engineering Librarian at Purdue University's Siegesmund Engineering Library, West Lafayette, Indiana. 
avoids duplicating the collection strengths of its various sites or of libraries with which it has resource-sharing agreements. The library system is a founding member of the Washington Research Library Consortium and the Virginia Academic Library Consortium.

A primary goal for the new library is the relief of overcrowding in the main campus library, Fenwick, as well as the expansion of Fenwick into a more research-centered library. The UCL would provide an attractive alternative for library users not needing extensive access to print collections. The decision was made to design a library that combined elements of an undergraduate library, a media center, and an electronic library. Early in the design process, the largest part of the library became a "library without walls," a place where users could freely move among food and other auxiliary services, student organization offices, library stacks, and seating. The guiding principle was that of providing an envi-

A faculty task force on the library of
the 21st century had recommended
that the library system pursue a
vision of an electronic library while
simultaneously developing a library
that could serve the needs of a
growing research program.

ronment in which students might experience something of a microcosm of their lives at GMU. While there are many studies on the development and administration of undergraduate libraries, there are no existing models for designing a university center library, which will attempt to bring together all the various components of the college experience under a single roof. ${ }^{1,2}$

Concurrent with the planning of the University Center was a re-examination of the general studies curriculum of the university, which led to the development of a set of core courses emphasizing interdisciplinarity and diverse cultural perspectives. Librarians served on each of the curriculum development committees, and helped identify materials in all formats necessary to support the core curriculum. Ultimately, this core curriculum was not adopted across the entire campus, but the principles that went into its formation continued to illuminate collection development decisions for the UCL. There were many factors considered in deciding what kinds of materials to collect for the UCL. The most important of these were that the materials:

- support the general education component of the undergraduate curriculum;

- be consciously selected to support the growing tendency toward interdisciplinary and multicultural curricula;

- support the increasingly active role the library was playing in the development of courses using technology and multimedia;

- be electronic and networked whenever possible;

- not needlessly duplicate the holdings of the main library but could do so when multiple copies were likely to be needed by patrons; and

- mirror in format and content, whenever possible, the overall ambiance of the building: casual, multicultural, and student centered. ${ }^{3}$

The general description of the collecting philosophy became "what you would buy for the library of a 21st-century citizen of the world if you could create a library of approximately 100,000 volumes." Additionally, a decision was made not to view the library as an archival collection, because security in the building would not support such a view and because that function would continue to be performed by the main library. On occasion, the phrase "disposable collection" has been used in order to emphasize the commitment of librarians and the university administration to the development of a working collection that would evolve 
with the needs of the university's programs.

Faculty of the university were involved in planning for the new library, even in its early, preconceptual stages. A faculty task force on the library of the 21st century had recommended that the library system pursue a vision of an electronic library while simultaneously developing a library that could serve the needs of a growing research program. Faculty have served on committees that developed the building program for the new structure, and continue to play an active role in decisions regarding the University Center's programming, organization, and mission. The library system was eager to bring faculty into the collection development process because there was substantial expertise available, and because the enthusiastic support of the work of the library by faculty would be key to its success.

\section{Collection Development Plan and Strategies}

With support from the provost, the director of libraries chartered a faculty task force in 1992 to advise the library on the formation and implementation of a collection development policy. Faculty members were chosen based on their knowledge of various cultural areas and their expertise on regions of the world. A task force of librarians, with subject expertise from the humanities, social sciences, and physical sciences, was also appointed to serve as a working group for the actual drafting of the policy and the development of the collection. Soon after the formation of the faculty committee and working group, the head of collection development, who chaired both, determined that both groups would function more effectively as a joint task force. The joint task force meets regularly throughout the academic year to discuss collection development strategies, while the working group of librarians meets frequently to monitor the process.

\section{Collection Development Policy}

Formation of the actual collection development policy statement began in the initial meetings of the faculty advisory committee and the working group. Utilizing both recent and current undergraduate education curriculum initiatives at the university, the working group drafted a preliminary document to share with the faculty advisory committee. This was a thorough presentation of the initial goals, detailing all of the areas of diversity, multiculturalism, core and foundation texts, and general education guidelines that were pertinent. After two planning meetings with the faculty advisory group, the librarians decided to distill the official policy statement down to its essentials. This would avoid any possible misconceptions that the collection would target any particular areas or disciplines. Through three or four subsequent drafts, the task force pared down the "Collection Strengths" section to its essential two components: 1) representative original texts and secondary materials that reflect North American, global, and thematic diversity; and 2) foundation texts in primary fields of study. (Complete policy statements are available from the authors.)

Instead of itemizing diversity by type or theme, or listing multiculturalism by regional ethnicity, the task force decided upon the first statement listed above. Similarly, the task force chose "foundation texts in primary fields of study" rather than list such areas as introductory texts, general education, and classic texts. The more detailed documentation, however, still provided working guidelines for the task force.

The "General Selection Guidelines" section of the policy was less difficult to conceptualize and included several components. The task force decided that original texts should comprise the majority of the collection. Languages taught at GMU would be well represented in the collection, mostly in literary works, to comple- 
ment the university's new initiative of teaching foreign languages across the curriculum. Strong emphases are being placed upon multimedia, including film and interactive discs, and upon electronic resources, particularly those that are full text. In fact, when the full strength of 100,000 volumes is reached by the end of the decade, it is envisioned that although the collection will continue to expand greatly, it will do so mainly in electronic formats.

\section{Faculty Involvement}

A key strategy in building a collection is, of course, to involve faculty as much as possible. First, the task force sent memos to all faculty requesting reading lists to allow selectors to benefit fully from the instructors' subject expertise and knowledge of sources. The task force encouraged faculty to add or delete items and to make notes regarding materials. In addition to reading lists, it was helpful to examine reserve lists from undergraduate courses to identify titles for purchase, since these items already had been deemed core items. A similar strategy is planned to examine supplementary readings for sale in the bookstore for undergraduate classes and to collect those that fit the collection emphases. These strategies closely involve faculty, either directly or indirectly, in the selection of materials and ensure that the collection is relevant to university teaching. The task force also wanted to seek input from other campus groups, including students and committees concerned with undergraduate education.

Foremost of the groups currently involved with expanding undergraduate educational options is a zero-base curriculum task force. This task force is charged with totally redesigning the undergraduate learning environment, beginning with 200 students in a self-paced learning track. ${ }^{4}$ Composed of three divisions, this program will offer units on higher education, the tangible world, society, and the individual and self. In addition, learning communities will be formed to study and teach various themes, e.g., utopias, violence. A final division will be closely tied to the majors and involve internships and cooperative and site-based learning. The UCL will offer integral support to this new program, through both its collection and its teaching mission. The collection will be augmented and changed as the curriculum changes, and staff will offer intensive bibliographic instruction to help students meet their research requirements. As noted earlier, a great many teaching faculty and librarians were involved in a former general education task force, identifying several hundred core titles appropriate for undergraduate study. All of these items are now part of the main library's collection and are likely candidates for transfer to the new library. Other campus groups representing curricular innovations such as the PAGE (Plan for Alternative General Education) Program and Mason Scholars (program for exceptionally gifted students) will also be consulted.

In addition to faculty reading lists and input from other campus groups, core bibliographies need to be examined in order to build up a strong retrospective collection. Books for College Libraries is still the most important single source for undergraduate collections. It does have limitations in that it is dated and somewhat weighted toward the humanities, but it can also be very useful in identifying core foundation works that may then be purchased in their latest editions. Faculty involvement in the process ensures that selections are relevant. A recent, extensive bibliography for ethnic studies collection development is the Choice Ethnic Review Series, including African American Studies, Latino Studies, and Native American Studies. More reviews are slated for publication and should prove beneficial. Multicultural Review is also useful, as are such various handbooks as African American Masterpieces and The Reader's Adviser, to 
help identify ethnic literature and regional or country studies. In combination with other strategies, selections from basic bibliographies fulfill an important role in developing a balanced collection.

\section{Key Series and Sets Identification}

Another excellent strategy is the identification of key series and sets. Series and sets may be customized to the collection development policy, but might include such standards as the Cambridge history sets; Cambridge thematic, literary, and philosophy sets; the PBS NOVA videotape collection; Great Books of the Western World; Encyclopedia of World Cultures; Library of America; Annals of America; and Modern Library. Series may include such titles as Feminist Press's Cross-Cultural Memoirs, Smithsonian Studies in the History of Film and Television, MacMillan Modern Novelists, G.K. Hall's Critical Essays on British Literature, Hill and Wang's Critical Issue Series, and the Virago Press series of women writers.

A particularly interesting project for this collection was the collecting of works of all Nobel Peace and Literature Prize winners in both the original language of the author and the English translation. For many of the most significant literature prize winners, this included all currently available works. The task force treated other writers somewhat more selectively, though usually including a large majority of their works. Unfortunately, for many of the early prize winners, there is very little still in print. For the Peace laureates, there is much less available, since many had not written for publication or had published research too advanced for undergraduate study. However, there is still a rich body of literature to choose from, and the resulting collection is an excellent selection of culturally diverse works of literature in several languages that encourage independent and collaborative study, as well as both breadth and depth of research. Similar projects could be undertaken to identify groups of great thinkers/writers of certain areas of the world, both past and present.

\section{Approval Plans}

To capitalize on the collection development efficiency of approval plans, the task force looked at the possibility of using approval plans in the initial planning stages. Though the efficiency of approval plans was appealing, there were legitimate concerns about the limited subject terms in existing plans, particularly in the areas dealing with diversity. At the outset, several questions arose. Should approval plans be used at all? If so, would more than one vendor be used? Would the vendors be willing to use GMU-selected subjects rather than limit the selection to their subject terms? Key to the decision was the determination that librarians, rather than the vendors, would select the gen-

Faculty involvement in the process ensures that selections are relevant.

eral areas and the specific subjects of any possible approval plan. The task force explored two components of a potential approval plan. A cultural diversity component of the plan would ideally include literature; political, social, cultural, and economic issues; geographic areas; and thematic studies.

The task force's vision of the literature collection is one of original works of authors representing North American cultural diversity as well as authors representing world cultural diversity. The political, social, cultural, and economic issues of diversity include collecting works on cultural studies, ethnic relations, civil rights, human rights, racism, sports and leisure studies, separatist movements, genocide studies, and intercultural relations. Wide representation of geographic areas including North America, Africa, the Middle East, Asia, the Pacific, Europe, Latin America, the Caribbean, Russia, and Eastern Europe is a major tenet of the col- 
lection. However, the overall emphasis of the collection will be on works representing North American cultural diversity in all of its multicultural and multiethnic facets. Thematic studies include works on indigenous peoples, gender studies, and religions of the world, as well as other themes relating to the multifaceted subject of cultural diversity.

The challenge for the task force involved translating its vision of these themes to the vendors of approval plans. Representatives of two approval plans met with the committee to outline their proposals. During the course of these meetings, the task force began to focus on which vendor could 1 ) best match the criteria for both the general themes and specific subjects, and 2) provide a person who would supervise the assessment and evaluation of titles selected. Both vendors presented attractive plans, and the task force considered a combination of plans

\section{In the case of multimedia, new and different criteria and selection sources will need to be established and consulted to ensure coverage of this rapidly developing and prolifer- ating medium, especially in the area of full-text materials.}

by using the best of each alternative. However, chiefly because of the real possibility of much duplication, the task force decided to use one vendor. The guarantee of personal supervision of the plan and flexibility in meeting the request for titles matching the general thematic approaches convinced the collection development committee that a unique approach to collecting for the UCL was possible, and an approval plan was implemented. The diversity portion of the plan provides the titles envisioned by the collection development task force to form the basis of a unique collection based on the many facets of cultural diversity.

A second component of the approval plan was necessary to cover the founda- tion or "core" texts in the major disciplines of the undergraduate curriculum. For the purpose of focusing the approval plan, the task force consulted with selectors to arrive at a working definition of core texts: foundation or core texts are books that have generally been recognized or accepted as providing fundamental knowledge about a discipline or part of a discipline, giving interpretation and context. They may be written by theorists, practitioners, or key writers, and should be appropriate for nonspecialist readers, specifically undergraduates. Foundation texts in the fields of science, engineering, and technology may or may not include problem sets and exercises.

This plan was set up to include introductory titles such as Introduction to Computer Engineering or Elementary Differential Equations. With this definition, a copy of the course catalog, and a copy of the collection policy statement, the vendor started sending slips for selection, which initially included retrospective titles dating back to 1990 . The working group as a whole reviewed the forms, and support for the approval plan has been overwhelmingly positive. The working group quickly remedied a few minor problems, such as elimination forms for children's titles.

The foundation text portion of the plan has been instrumental in building up core titles from 1990 to the present. Procedures have also been implemented to coordinate the library's main approval plan with the smaller plan. Subject specialists routinely review books on the main plan to determine whether a foundation text belongs in the UCL or in Fenwick Library. In many cases, a title may be chosen for both libraries, and procedures for this are in place.

\section{Duplication}

The issue of duplication between the two collections arose early in the deliberations and generated much discussion. A certain 
amount of duplication is both necessary and desirable, but these considerations must be made at each step in the process. Initially, with limited funds, the task force focused on ordering unique titles for the UCL. As more funds became available, however, the task force developed guidelines for the selectors to help them decide when to order duplicates. It was decided that Fenwick Library, as the archival research library, should have a copy of all titles most appropriate for advanced undergraduate and graduate research study. The UCL would be the choice for all titles that fall within the scope of its collection development policy and are expressly targeted to beginning researchers. In the many cases that are not clear cut or may overlap, selectors are instructed to choose the title for Fenwick Library and to order a second copy for the UCL if the title is deemed important. The notable exceptions to these guidelines are the UCL's massive reserve component and certain areas of literature, which will be largely composed of duplicate titles. To take advantage of existing duplicate titles within the Fenwick collection, the systems office generated a list of titles in the collection that have two or more copies. This list, divided by call number, was reviewed by the selectors, who selected titles to be tagged and transferred to the new collection. In addition to using existing resources, this strategy has the advantage of mitigating space problems in the main library. A closely related strategy involves reviewing books that are donated to the library for possible addition to the new collection.

\section{Media Selection}

Another strategy involves selecting media resources. Though the entire media collection will move from the main library to the UCL, it will still be necessary to ensure that the new library has a balance of formats covering those areas outlined in the collection development policy. Selectors chose hundreds of films from na- tional and oppositional cinemas throughout the world for purchase in VHS or laser disk format, as well as many documentaries and experimental films dealing with areas of diversity. Recordings of ethnic and indigenous music and dance, representing cultures around the world, are being identified for purchase as well. In the case of multimedia, new and different criteria and selection sources will need to be established and consulted to ensure coverage of this rapidly developing and proliferating medium, especially in the area of full-text materials.

A final strategy involves selecting electronic databases and full-text resources for the UCL, which means that the new library must keep abreast of the many text-encoding initiatives and projects rapidly developing and proliferating today. Most, if not all, of the selected databases would duplicate what is already available in the main library, and the task force plans to expand existing networking licenses to include the new library. These electronic resources will include a variety of bibliographic, full-text, and image databases that will make the integrated scholar workstation a reality.

\section{Statistical Profile}

To monitor the selection process and ensure balance among subject areas and formats, the working group developed a detailed record-keeping system in order to provide an accurate, ongoing statistical profile of the collection. The working group assigned each item ordered to one of eighteen categories within North American, global or thematic diversity, or to one of three areas under foundation texts. Each item then was also assigned to either humanities, social science, or science materials, and listed as either book or nonbook. Large sets of materials in paper (Great Books of the Western World) or in electronic format (Library of the Future) were counted as many individual works. Keeping this snapshot view of the collection allows the committee to concentrate 
on the development of certain areas of the collection from year to year.

After developing initial strategies, setting priorities, and putting policies into place, collection development for a new library is easily incorporated into existing procedures. It was recently decided, after much discussion among the librarians in the working group (particularly with the newest member, the University

While the real test will occur only after the library opens, the collection development plan appears to support the library's response to the new educational challenges of the 21st century.

Center librarian) to mesh much of the selection process with that of the main library. This would allow the bulk of the selection to be done by the subject specialists, many of whom are part of the working group. The selection areas that remain separate from the main library's collection development process include the diversity approval plan and a media fund.

\section{Conclusion}

This paper outlines the basic strategies that a task force developed to build a core collection of multicultural, foundation, and multimedia materials for a state-ofthe-art electronic University Center Library. The basic strategies pursued by the task force in designing and implementing the collection development plan can be summarized as follows:

- drafting a collection development policy that lays out the fundamental objectives and sets up essential guidelines for the collection,

- involving faculty members in the collection process to guarantee that the collection meets the demands of university curriculum and campus teaching needs,

- examining core bibliographies to construct a solid retrospective component of the collection, especially in the humanities and social sciences,

- identifying key series and sets to keep the collection up to date and to purchase the most relevant new publications, and

- establishing an approval plan to take advantage of subject profiling and timely notification.

Planning a collection for a new library requires a full and thorough understanding of the mission of the new library and the clientele it will serve. Preliminary use of the collection indicates that the initial collection development policy and procedures have been successful. According to a recent ARL study, "seventy-four percent of responding libraries said that ethnic materials are in demand." ${ }^{15}$ Both the multicultural and foundation portions of the collection are currently stored in closed stacks until the opening of the library. Statistics for patron requests, which are filled within twenty-four hours, indicate that a large portion of the collection is heavily used. While the real test will occur only after the library opens, the collection development plan appears to support the library's response to the new educational challenges of the 21st century.

As Larry Hardesty and Collette Mak point out in "Searching for the Holy Grail," there is little consensus among libraries on core undergraduate collections. ${ }^{6}$ However, thanks to the joint efforts of the task force and faculty members, and the full support of the library administration, the collection development strategies mentioned above are working very well for the new University Center Library at George Mason University. These strategies could be customized to meet the needs of other institutions undergoing similar developments. Preparing for the future in higher education is always a challenging and intricate process, but with careful planning and widespread involvement of the campus community, it may be a rewarding one as well. 


\section{Notes}

1. For additional information see, Roland Conrad Person, A New Path: Undergraduate Libraries at United States and Canadian Universities, 1949-1987 (New York: Greenwood Pr., 1988); Patricia Tarin, "The Good, the Undergrad, and the UGLi," Library Journal 115 (Oct. 1990): 51; Carla Stoffle, "A New Library for the New Undergraduate," Library Journal 115 (Oct. 1990): 47-50; and Larry Hardesty, Faculty and the Library: The Undergraduate Experience (Norwood, N.J.: Ablex Publishing, 1991).

2. For additional information on the University Center Library, see Charlene S. Hurt, "A Vision of the Library of the 21st Century," Journal of Library Administration 15 (Mar./Apr. 1991): 7-10.

3. See for example, Otis Chadley, "Addressing Cultural Diversity in Academic and Research Libraries," College \& Research Libraries 53 (May 1992): 206-14; Karan Parrish and William Katz, Multicultural Acquisitions (New York: Haworth Pr., 1993); and Donald Riggs and Patricia Tarin, Cultural Diversity in Libraries (New York: Neal- Schuman, 1994).

4. See the following for more information on similar efforts to restructure the curriculum: Paul Astin, Interdisciplinarity: Education for Social Consciousness, ERIC Document Reproduction Service, no. ED 283450 (1986); Leon Botstein, "Structuring Specialization As a Form of General Education," Liberal Education 77 (Mar./Apr. 1991): 10-19; Renewing Undergraduate Education: Recommendations from the Irvine Group, ERIC Document Reproduction Service, no. ED 328194 (1990); and William Toombs and William Tierney, Meeting the Mandate: Reviewing the College and Departmental Curriculum ASHE-ERIC Higher Education Report, no. 6. ERIC Document Reproduction Service, no. ED 345603 (1991).

5. Chadley, "Addressing Cultural Diversity," 211.

6. Larry Hardesty and Collette Mak, "Searching for the Holy Grail: A Core Collection for Undergraduate Libraries," Journal of Academic Librarianship 19 (Sept. 1993): 362-71.

\section{Use INTERNET to}

\section{UnCover...}

\section{UnCover}

6 million articles from 20,000 multidisciplinary periodicals delivered by fax in 24 hours or less
UnCover Reveal

Electronic TOC service with user profiling

UnCover
Complete
Pre-1989 journals
can be ordered
online

\section{UnCover SOS}

Order articles by fax, phone, e-mail or post from UnCover's Single Order Source service

The UnCover Company

E-mail: uncover@carl.org

3801 East Florida Avenue, Suite 200 口 Denver, CO 80210, USA

Phone: I-800-787-7979 व Fax: 303-758-5946

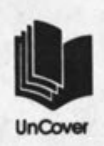

Readmore, Inc.

22 Cortlandt Street

New York, NY 10007

...Articles

Phone: I-800-22I-3306

UnCover is a service of Readmore, Inc. 


\section{A New Service on the Information Superhighway}

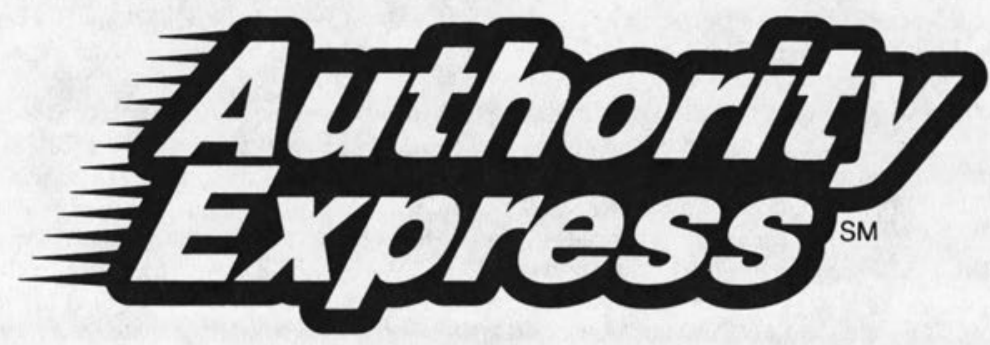

If you have been searching for an easy way to authority control your library's current cataloging, try LTI's Authority Express service.

With Authority Express, a library uses the Internet to transmit a file of newly cataloged bibliographic records to LTI (via FTP). Overnight, LTI processes the records through its state-of-the-art authority control system. Then, at the library's convenience, it logs into LTI's FTP server to retrieve fully authorized catalog records, along with linked LC name and subject authority records.

\section{Authority Express}

- Keeps authority control current at an affordable price

- Integrates easily into existing workflows

- Lowers cost by reducing staff time spent on catalog maintenance

- Provides next-day turn around for up to 5,000 catalog records

- Accepts records for processing even if LTI did not perform the original authority control

"Authority Control for the 21st Century"

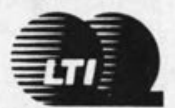

\section{LIBRARY TECHNOLOGIES, INC.}

1142E Bradfield Road Abington, PA 19001

(215) 576-6983 Fax: (215) 576-0137

(800) 795-9504 email: LTI@LibraryTech.Com 